\title{
Designs of borders: Security, critique, and the machines - CORRIGENDUM
}

\author{
Médéric Martin-Mazé1* and Sarah Perret ${ }^{2}$ \\ ${ }^{1}$ Université Paris VIII Vincennes - Saint-Denis, LabToP-CRESPPA, France and ${ }^{2}$ King's College London, United Kingdom \\ and Chair in Geopolitics of Risk, ENS Paris, France \\ ${ }^{\star}$ Corresponding author. Email: mederic.martin-maze@univ-paris8.fr
}

(First published online 9 February 2022)

doi:10.1017/eis.2021.8, published online by Cambridge University Press, 28 April 2021.

Keywords: Border; Security Research; Technology; European Union; Critique

The author omitted some details in the acknowledgments section and would like to rectify the first sentence to read as follows:

"This research benefited from the support of the EC-funded SOURCE programme and from the European Research Council (ERC) under the European Union's Horizon 2020 research and innovation programme (SECURITY FLOWS, grant agreement No 819213).”

The author apologises for this error.

\section{Reference}

Martin-Mazé, M., \& Perret, S. (2021). Designs of borders: Security, critique, and the machines. European Journal of International Security, 6(3), 278-300. doi:10.1017/eis.2021.8

Cite this article: Martin-Mazé, M., Perret, S. 2022. Designs of borders: Security, critique, and the machines CORRIGENDUM. European Journal of International Security 7, 411-411. https://doi.org/10.1017/eis.2022.5

(c) The Author(s), 2022. Published by Cambridge University Press on behalf of the British International Studies Association. 